\title{
Assessment of the level of seminal zinc and fructose concentration in seminal plasma of Vietnamese infertile men
}

\begin{abstract}
This study assessed the association between the fructose and zinc concentration and various seminal characteristics. Fructose and zinc in semen reflects the secretary function of seminal vesicles. These Tests may help in assessing the diagnosis and the management of male infertility. Gather seminal plasma of 180 males with average age of $31.1 \pm 3$,6years old. Use the specific complex ant to form a stable colored complex with fructose or zinc. The colour intensity in a determining wavelength is proportional to the amount of fructose or zinc present in the sample. Seminal fructose concentration was significantly lower in oligozoospermic group and the azoospermic group in comparison with normozoospermic group. There are also many significant differences in Zinc's concentration in semen when compared two in term of three groups, consist of the oligospermic, azospermic and normospermic group. Sperm DNA fragmentation index in-group with normozospermia correlated positively with seminal fructose $(\mathrm{r}=0.47, \mathrm{P}<0.05)$ and negatively with seminal zinc $(\mathrm{r}=-0.56, \mathrm{P}<0.05)$ concentrations. In group with oligozospermia found negative correlation $(\mathrm{r}=-0.24, \mathrm{P}<0.05)$ between seminal fructose with sperm DNA fragmentation. In addition, there were 3 patients with Klinefelter syndrome in group with non-obtructive azoospermia with elevated seminal fructose concentration.

The role of seminal fructose concentration does not only lie in the assessment of seminal vesicle dysfunction but also in conjunction with other seminal properties could give a useful indication of male reproductive function whilst seminal zinc concentration might not be most appropriate for the assessment of male reproductive dysfunction. This is the first study to demonstrate that the increase of seminal fructose and decrease of zinc concentrations may reflected by high sperm DNA damage. This is the first report of increased in seminal fructose concentration in seminal plasma from the azoospermic men with Klinefelter's syndrome.
\end{abstract}

Keywords: infertility, seminal fructose, seminal zinc, azoospermia
Volume 2 Issue 4 - 2018

\author{
Nguyen Thi Trang, 'Trieu Tien Sang, ${ }^{2}$ Nguyen \\ Hoang, ${ }^{3}$ Nguyen Tan Gia Khanh, ${ }^{4}$ Tran Trung \\ Duc $^{4}$ \\ 'Department of Biomedical and Genetics Hanoi Medical \\ University Hospital,Vietnam \\ ${ }^{2}$ Vietnam Military Medical University, Vietnam \\ ${ }^{3}$ Hanoi Amsterdam High School for Gifted Students, Vietnam \\ ${ }^{4} \mathrm{HUS}$ High School for Gifted Students, Vietnam
}

\begin{abstract}
Correspondence: Nguyen Thi Trang, Department of Biomedical and Genetics, Hanoi Medical University, N. I, Ton That Tung, Dong Da, Hanoi,Vietnam, Tel +84I6 3878 8736,
\end{abstract} Email trangnguyen@hmu.edu.vn

Received: July 06, 2018 | Published: August 032018
Abbreviations: CBAVD, congenital bilateral absence of the vas deferens; PESA, percutaneous epididymal sperm aspiration; DFI, DNA Fragmentation Index; HCl, hydrochloric acid; SPSS, statistical package for the social sciences

\section{Introduction}

Infertility is defined as the failure of a couple to achieve a pregnancy after at least one year of frequent unprotected intercourse. ${ }^{1,2}$ It has been reported that the male partner contributes in $40 \%$ of the cases of infertility. Globally, the incidence of fertility is estimated to be about $13-18 \%{ }^{1,3}$ Due to the various reasons caused male infertility, it is essential to identify appropriate diagnosis methods to detect them. There are many tests that have been applied for several decades such as semen analysis, genetic tests and hormones methods. Recently, some of biochemical markers including zinc and fructose are becoming significant implications for diagnosing the cause in male infertility. ${ }^{4}$ They have thus been established as good indicators of human male fertility. An understanding of the factors affecting these characteristics is critical to proper understanding of the mechanisms underlying male infertility. ${ }^{5,6}$
Fructose is essential for spermatozoa metabolism and spermatozoa motility. ${ }^{7}$ Fructose is an energy source for spermatozoa. It is produced by the seminal vesicles with some contribution from the ampulla of the ductus deferens. ${ }^{8,9}$ Determination of seminal fructose concentration has been used in examination of obstructive azoospermia and inflammation of male accessory glands. ${ }^{10,11}$ The role of fructose concentrations in seminal plasma for total and sperm density has been investigated by several authors. Rajalakhshmi M, et al., ${ }^{12}$ and Gonzales ${ }^{13}$ reported that an increase in sperm concentration is often accompanied by a decrease in fructose concentration in seminal plasma, because sperm using fructose as the primary source of energy, ${ }^{12,13}$ However, others studies have also shown that fructose concentrations in seminal plasma of patients with oligozoospermia and azoospermia did not decrease as compared to normal men.

Apart from fructose, zinc is another factor essential for male reproductive system. Deficiency of zinc in the reproductive system causes hypogonadism and gonadal hypofunction. ${ }^{14,15}$ Many studies have shown that zinc plays an important role in the normal development of testicles, prostate and sperm motility. ${ }^{9,16}$ However, in Vietnam, the knowledge about relationship between seminal zinc and 
fructose concentration on human sperm characteristic is insufficient and scanty. Therefore, the purpose of this study was to determine the association between the fructose and zinc concentration and various seminal characteristics in men. From there, we recommend determining the concentration of fructose and zinc for male infertility diagnosis with abnormalities on semen analysis.

WHO 2010 divided male infertility into 3groups: normozoospermia (sperm concentration $>=15$ billion $/ \mathrm{ml}$ ), oligozoospermia (sperm concentration $<15$ billion $/ \mathrm{ml}$ ) and azoospermia (no sperm). ${ }^{16}$ There are many studies determined seminal fructose and its correlations with concentration, vitality and motility of sperm. Azoospermia is the reason in $20 \%$ infertility $\operatorname{man}^{17}$ and the common reason of azoospermia is CBAVD. ${ }^{12,18}$

\section{Materials and methods}

\section{Objects}

Study design was descriptive research. Fructose and Zinc concentration in seminal plasma of 180 patients with average age of 31.1 \pm 3 ,6years old. visited in Fertility Department of Hanoi Medical University Hospital after accomplished semen analysis with abnormalities sperm characteristic (sperm concentration, total count, motility, progressive motility) from March, 2016 to March, 2017, were used for study. All the samples were performed according to the World Health Organization criteria (1992). On the basis of the assessed parameters, sperm concentration and sperm motility were considered as the important parameters.

\section{Measuring the concentration of fructose and zinc}

The participants of the study were asked to produce sperm by masturbation and collected in sterile container with period of 2-5days of intercourse abstinence. Sperm should be analyzed within 2 hours after produced. Routine semen analysis was performed according to WHO 2010 guidelines. After the semen analysis, samples were centrifuged at $1500 \mathrm{x}$ g for $10 \mathrm{~min}$ and zinc and fructose concentrations assayed from the supernatant (i.e. seminal plasma). Zinc concentration was assessed using spectrophotometry (5- Br- PAPS method) - direct colorimetric test without deproteinization of the sample. At $\mathrm{pH} 8.6$, in a buffered media, zinc reacts with specific complexant 5-Br-PAPS form a stable color compound. Fructose content in seminal plasma was determined by the resorcinol method where fructose reacts with resorcinol in concentrated hydrochloric acid $(\mathrm{HCl})$ solution to form a red compound. Measure the coloric complex of Zinc and Fructose at a wavelength of $560 \mathrm{~nm}$ against blanks (ROE, 1976). ${ }^{19}$ Semen samples were collected for routine semen analysis and sperma DNA Fragmentation Index (DFI) testing. Technique of sperm DNA fragmentation test using Halosperm kit (Halotech Madrid, Spain).

\section{Statistical analysis}

Statistical analysis was performed using SPSS version 16.0. The means were compared using student $t$ test. The statistical tests were considered to be significant at the $\mathrm{p} \leq 0.05$ level.

\section{Ethical considerations}

Ethical approval to conduct the study was sought from the Hanoi Medical University. Permission to use data from the Hanoi Medical University Hospital was sought from the hospital authority. All the information from the database was kept under strict confidentiality. No names were recorded.

\section{Results}

\section{Fructose concentration and seminal parameters}

Table 1 shows that seminal fructose in oligozoospermia was significantly higher than normozoospermia $(\mathrm{p}<0.05)$. Besides, the mean sperm concentration $(133.808 \pm 48.215$ millions $/ \mathrm{mL})$, and the mean vitality $(86.483 \pm 3.218 \%)$ and the mean progressive motility $(11.250 \pm 10.157 \%)$ in males with normozoospermia were significantly higher than that in males with oligozoospermia ( $5.633 \pm 4.992$ millions/ $\mathrm{mL}$ and $58.183 \pm 18.14 \%$ and $11.250 \pm 10.157 \%$ respectively) $(\mathrm{p}<0.01)$.

Some sperm characteristic and seminal fructose concentration were demonstrated in charts. The results show the correlation is significant at the 0.05 level (2-tailed) between seminal fructose concentration and sperm progressive motility $(\mathrm{z}=-0.183 ; \mathrm{p}<0.05)$ (Spearman test) (Figure 1) (Figure 2) (Figure 3).

All 25cases azoospermia without seminal fructose have been examined and precede percutaneous epididymal sperm aspiration (PESA) by anthologist to find the infertility reason. The result shows that the reason in all the cases is Congenital Bilateral Absence of the Vas Deferens (CBAVD). Fructose concentration in 25cases with obstructive azoospermia is lower than normal or zero. By other side, 35 cases with non-obtructive azoopermia, fructose concentration usually higher or equal than normal. In addition, there were 3 patients with Klinefelter syndrome in group with non-obtructive azoospermia with elevated seminal fructose concentration.

Table I Seminal fructose and some characteristics of the semen

\begin{tabular}{llll}
\hline $\begin{array}{l}\text { Group } \\
\text { variables }\end{array}$ & $\begin{array}{l}\text { Normozoospermia } \\
(\mathbf{n = 6 0 )}\end{array}$ & $\begin{array}{l}\text { Oligozoospermia } \\
(\mathbf{n = 6 0})\end{array}$ & $\mathbf{P}$ \\
\hline Fructose (g/L) & $1.601 \pm 0,604$ & $1.881 \pm 0,640$ & $<0.05$ \\
$\begin{array}{l}\text { Sperm DFI } \\
(\%)\end{array}$ & $30.84 \pm 17,54$ & $21.09 \pm 11,18$ & $<0.01$ \\
$\begin{array}{l}\text { Sperm } \\
\text { concentration } \\
\text { (billion/ml) }\end{array}$ & $133.808 \pm 48,215$ & $5.633 \pm 4,992$ & $<0.001$ \\
$\begin{array}{l}\text { Vitality (\%) } \\
\text { Progressive }\end{array}$ & $86.483 \pm 3,218$ & $58.183 \pm 18,114$ & $<0.001$ \\
motility (\%) & $54.667 \pm 9,278$ & $11.250 \pm 10,157$ & $<0.001$ \\
\hline
\end{tabular}

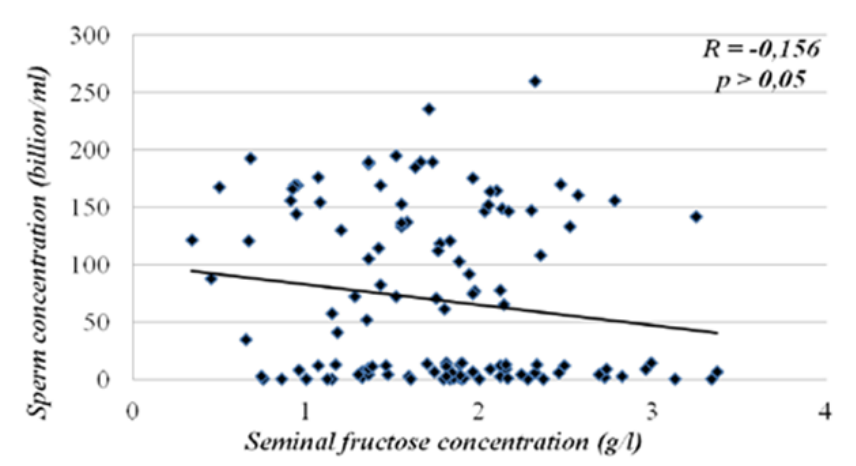

Figure I Correlation between seminal fructose concentration $(g / L)$ and sperm concentration (billion/ml). 


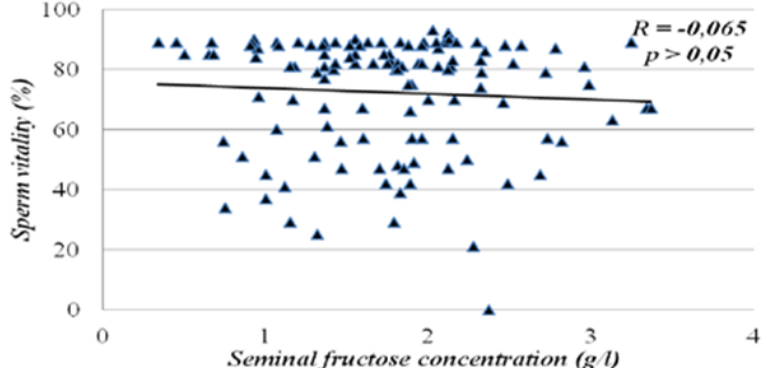

Figure 2 Correlation between seminal fructose concentration $(\mathrm{g} / \mathrm{L})$ and sperm vitality (\%).

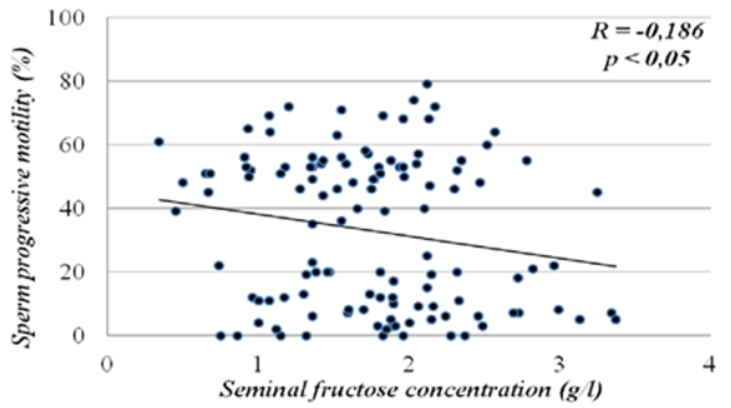

Figure 3 Correlation between seminal fructose concentration $(\mathrm{g} / \mathrm{L})$ and sperm progressive motility (\%).

\section{Zinc concentration and seminal parameters}

The Table 2 shows the following:

i. The progressive mobility of the low zinc concentration group was $16.87 \pm 10.67 \%$, lower than that of the normal zinc concentration group $(49.93 \pm 15.35 \%)$. This difference is statistically significant with $\mathrm{z}=-11.481(\mathrm{p}<0.01)$

ii. There was no statistically significant difference in the mean non- progressive motility in males with low zinc concentration compared to males with normal zinc concentration $(\mathrm{p}=0.19)$.

iii. \% DFI are lower in the oligozoospermic (21.09\%) compared with the normozoospermic (30.84) men (Figure 4) (Figure 5).

The low zinc concentration group had an immotile percentage of $73.00 \pm 21.42 \%$ was higher than the normal zinc concentration group $(44.07 \pm 15.43 \%)(\mathrm{z}=10.433)$. This difference was statistically significant with $\mathrm{p}<0.001$. Seminal zinc concentration showed a significant positive correlation $(\mathrm{r}=0.596)$ with sperm progressive motility $(p<0.01)$ Negative correlations were observed with sperm immotile $(\mathrm{r}=-0.527)$ with statistical significance $(\mathrm{p}<0.01)$.

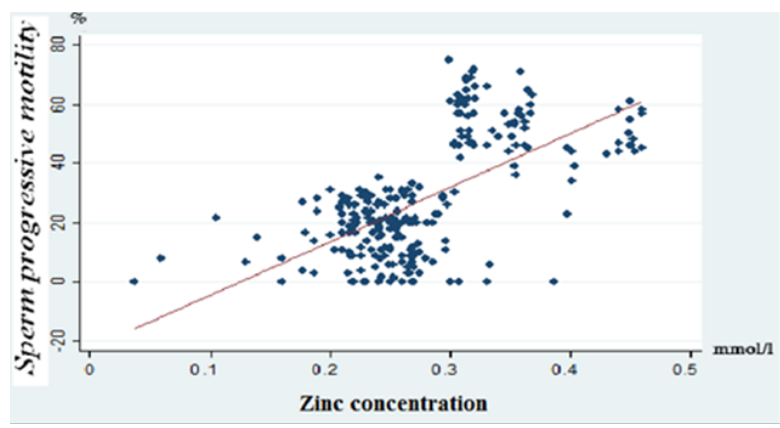

Figure 4 Correlation between seminal zinc concentration $(\mathrm{mmol} / \mathrm{L})$ and sperm progressive motility $(\%)(r=0,596 ; p=0,0000 I)$.
Table 2 Seminal zinc concentration and motility of the sperm

\begin{tabular}{lllll}
\hline Group motility & $\begin{array}{l}\text { Low zinc } \\
\text { concentration } \\
(\mathbf{m m o l} / \mathbf{L})(\mathbf{n} \\
\mathbf{= 8 4}\end{array}$ & $\begin{array}{l}\text { Normal zinc } \\
\text { concentration } \\
\mathbf{( m m o l / L )}(\mathbf{n} \\
\mathbf{9 9 6})\end{array}$ & $\mathbf{z}$ & $\mathbf{P}$ \\
\hline $\begin{array}{l}\text { Progressive motility } \\
(\%)\end{array}$ & $16.87 \pm 10,67$ & $49.93 \pm 15,35$ & $-11,48 \mid$ & 0.00001 \\
$\begin{array}{l}\text { Non- progressive } \\
\text { motility (\%) }\end{array}$ & $3.64 \pm 2,07$ & $4.07 \pm 4,63$ & $-1,301$ & 0.193 \\
& $73.00 \pm 21,42$ & $44.07 \pm 15,43$ & 10,433 & 0.0001
\end{tabular}

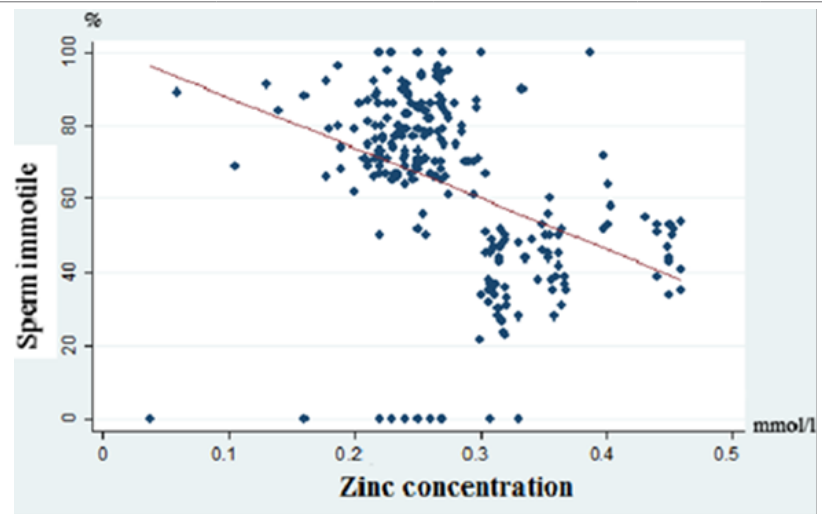

Figure 5 Correlation between seminal zinc concentration $(g / L)$ and sperm immotile $(\%)(r=-0,527 ; p=0,000 I)$.

\section{Correlation between seminal fructose and zinc with sperm DNA fragmentation}

Sperm DNA fragmentation index in group with normozospermia correlated positively with seminal fructose $(\mathrm{r}=0.47, \mathrm{P}<0.05)$ and negatively with seminal zinc $(\mathrm{r}=-0.56, \mathrm{P}<0.05)$ concentrations. In group with oligozospermia found negative correlation $(\mathrm{r}=-0.24$, $\mathrm{P}<0.05$ ) between seminal fructose with sperm DNA fragmentation (Table 3).

Table 3 Relationship between seminal fructose and zinc with sperm DNA fragmentation

\begin{tabular}{lcl}
\hline Group & $\mathbf{r}$ & $\mathbf{p}$ \\
\hline Fructose concentration $(\mathrm{g} / \mathrm{L})$ & and DFI (\%) & \\
\hline Oligozospermia $(\mathrm{n}=60)$ & -0.24 & $<0.05$ \\
Normozospermia $(\mathrm{n}=60)$ & 0.47 & $<0.05$ \\
\hline Zinc concentration (mmol/L) and DFI (\%) & \\
\hline Oligozospermia $(\mathrm{n}=60)$ & -0.08 & $>0.05$ \\
Normozospermia $(\mathrm{n}=60)$ & -0.56 & $<0.05$ \\
\hline
\end{tabular}

\section{Discussion}

Fructose is a main carbohydrate source in seminal plasma and necessary for sperm motion. ${ }^{20,21}$ The measurement of seminal fructose has been used in most laboratories. Therefore, the World Health Organization manual recommends measurement of seminal fructose as a marker of seminal vesicular function. ${ }^{22}$ Methods for determination of seminal fructose mainly includes gas chromatography, indole coloration, and resorcinol coloration. In particular, the resorcinol method has been used widely in clinical anthology laboratories for its simplicity of operation, high specificity, and no need for special instrument. Fructose in semen is the source of energy for all sperm activities. The higher of sperm concentration, and vitality and motility 
asked for more energy, so fructose is lower. ${ }^{9,23}$ Normal seminal fructose concentration confirms the role of testosterone and the function of vesicles and vas deferens are normal. ${ }^{24}$

In this study, negative correlations were observed between seminal fructose and sperm concentration $(R=-0,156$ và $p>0,05)$, sperm vitality $(\mathrm{R}=-0,065$ và $\mathrm{p}>0,05)$ and sperm progressive motility $(\mathrm{R}=-0,186$ và $\mathrm{p}<0,05)$. This finding is in line with that of Gonzales ${ }^{13}$, Orakwe, et al., ${ }^{25}$ and Mahmoud, et al., ${ }^{26}$ Fructose in semen is the source of energy of every sperm activities. The higher of sperm concentration, vitality and motility asked for more energy, so fructose is lower. ${ }^{23,27}$ $\mathrm{Lu}$ (2007) reported seminal fructose concentration decreased, sperm concentration and mobility increased. ${ }^{23}$

Lewis Jones, et al., ${ }^{6}$ found that fructose concentrations were inversely ratio to sperm motility with $\mathrm{R}=-, 062(\mathrm{p}<0.05) .{ }^{6}$ However, Andrade Rocha FT (2001) confirmed that seminal fructose concentration was related to sperm concentration, survival, motility and morphology, but the results were not statistically significant. ${ }^{28}$ In the study of Amidu N (2012), seminal fructose concentration was negatively correlated with sperm motility $(\mathrm{R}=-0.04)$ but not statistically significant. ${ }^{29}$ Fructose concentrations were inversely ratio to sperm concentration $(\mathrm{R}=-0.21)$ with correlation was significant at 0.05 level. ${ }^{30}$ Fructose is the major glycolysable substrate of seminal plasma and is widely accepted as a marker of seminal vesicle function. ${ }^{29-31}$ Inflammation may lead to atrophy of the seminal vesicles and low seminal fructose concentration. When ejaculatory ducts are blocked, fructose concentration in seminal plasma usually decreases and may become undetectable. ${ }^{29,32}$ Additionally, seminal plasma fructose concentration determination is useful for auxiliary diagnosis of obstructive and no obstructive azoospermia. Seminal fructose concentration in non-obstructive azoospermia is usually higher than or equal to that in males of normal fertility. ${ }^{33}$ However, fructose concentration in seminal plasma of patients with obstructive azoospermia is usually absent or significantly lower than that in men of normal fertility. ${ }^{29,31}$ Absence of seminal fructose has also been found in patients with congenital vas deferens-seminal vesicle developmental defect. ${ }^{18,34}$ Therefore, our results are consistent with most of the results of studies in the world.

Normal seminal fructose concentration confirms the role of testosterone and the function of vesicles and vas deferens are normal. ${ }^{31}$ The absence of both sperm and fructose correlates with the obstruction in CBAVD or retrograde ejaculation. ${ }^{1,13}$ Especially, the correlation between azoospermia and fructose in CBAVD had been proved by many authors. ${ }^{9}$ In this study, all 25 cases azoospermia without seminal fructose have been examined and precede percutaneous epididymal sperm aspiration (PESA) by anthologist to find the infertility reason. The result shows that the reason in all the cases is CBAVD. Fructose concentration in obstructive azoospermia cases is lower than normal or absent. ${ }^{11}$ By other side, In human with non-obtructive azoopermia, fructose concentration usually higher or equal than normal. ${ }^{11}$ Inflammation the reproductive glands causes temporary obstruction, so that sperm count and seminal fructose concentration may decrease, but rarely absence both of them. . $^{11,35,36}$

One of the biochemical processes related to the genital fluid mixing is the regulation of the free seminal zinc fraction, which can interact with spermatozoa, such as, zinc and bioavailability. Zinc is first secreted in prostatic fluid in 2 forms available for sperm cells (free zinc and zinc-citrate complex). During ejaculation, however, a partial redistribution of the ion from citrate to very high affinity vesicular ligands reduces the unbound zinc fraction. ${ }^{37-39}$ The measurement of zinc in human seminal plasma is important in the evaluation of male infertility. In present study the seminal plasma zinc levels were found to be immotile percentage in zinc concentration group was higher $(73.00 \pm 21.42 \%)$ than the normal zinc concentration group $(44.07 \pm 15.43 \%)(\mathrm{z}=10.433)$.

A positive correlation between seminal plasma zinc levels and sperm concentration, motility was also observed in our study. This was in accordance with the previous studies of Fuse (1999), Chia (2000), Basil (2008), N. Amidu (2012). ${ }^{40-42}$ Eliasson and Lindholme et al., in contrast could not find any correlation between zinc concentration and sperm density, motility or morphology. ${ }^{43}$ Some others authors not find the same results, but also agreed that zinc affects sperm motility. Omu (1998), Mahmoud Hussein Hadwan (2013), found that sperm motility increased after those subjects were given zinc supplements. ${ }^{44,45}$ Omar F. Abdul-Rasheed (2009), could not find correlation between zinc concentrations in semen and sperm mobility. ${ }^{46}$

Fuse et al. (1999) found positive correlation of zinc concentration with sperm concentration $(\mathrm{r}=0.33, \mathrm{p}<0.05)$ and with sperm motility $(\mathrm{r}=0.22, \mathrm{p}<0.05)$, while there was no correlation with sperm morphology and high zinc concentration is apparently related to defective motility in asthenozoospermic patients, even though adequate seminal plasma content of the element is required for normal sperm function. ${ }^{41}$ Mankad et al., found significant positive correlation was observed between zinc levels and sperm count $(r=0.29, \mathrm{p}<0.05)$ and zinc and alpha-glucosidase activity $(\mathrm{r}=0.31, \mathrm{p}<0.05)$ in seminal plasma. $^{47}$

Thus it seems that zinc is important for semen quality. The low zinc levels in the infertile men in our study might be attributed to disorders in the prostate excretory function or possibly due to asymptomatic prostate infection. Omu (1998), Mahmoud Hussein Hadwan (2013) and others found that sperm motility increased after treatment with zinc supplementation. ${ }^{48-53}$ However, Omar F. Abdul-Rasheed (2009) found not correlation between zinc concentrations in semen and sperm motility. ${ }^{54}$

We also observed that mean $\%$ DFI is higher in the normozoospermic compared with the oligozoospermic men. Seminal fructose correlates positively with spermatozoa DNA fragmentation, ${ }^{55}$ and has been found to be both significantly up- and down-regulated in different aetiologies of male infertility. ${ }^{56,57}$ In this study, found that seminal fructose level $(r=0.47, \mathrm{P}<0.05)$ correlated positively with sperm DNA fragmentation index in group with normozospermia. In group with oligozospermia found negative correlation $(r=-0.24, \mathrm{P}<0.05)$ between seminal fructose with sperm DNA fragmentation. In addition, there were 3patients with Klinefelter syndrome in group with nonobtructive azoospermia with elevated seminal fructose concentration. Thus, the change in seminal fructose concentrations may reflect by high sperm DNA damage. Increased fructose levels in the group with azoospermia may be associated with Klinefelter's syndrome.

Zinc is a metalloprotein cofactor for DNA-binding proteins with $\mathrm{Zn}$ fingers. It is part of copper $(\mathrm{Cu}) /$ zinc superoxide dismutase, and several proteins are involved in the repair of damaged DNA and transcription and translation processes of DNA..$^{58,59} \mathrm{Omu}$ et al., found that the in-vitro induced oxidative stress was caused by a combination of zinc deficiency and high level of sperm DNA fragmentation and apoptosis. ${ }^{60}$ In present study, we found negative correlation between 
seminal zinc concentration with sperm DNA fragmentation index. In the human reproductive system, zinc plays an important role in spermatogenesis, from its formation and contribution to the ultra structural stabilization of chromatin compaction to the modulation of mitochondria-dependent processes, such as cell respiration and programmed cell death.

\section{Conclusion}

Seminal fructose concentration of normozopermia group is significant lower than oligozoospermia group. Fructose seminal concentration has a negative correlation with sperm concentration, and vitality and motility. Fructose is the major glycolysable substrate of seminal plasma and is widely accepted as a marker of seminal vesicle function. The progressive motility in the low zinc concentration group is significant lower than that of the normal zinc concentration group. The immotile in the low zinc concentration group is significant higher than that of the normal zinc concentration group. Zinc concentration has a positive correlation with sperm progressive motility and a negative correlation with immotile both are statistically significant This is the first study to demonstrate that the increase of seminal fructose and decrease of zinc concentrations may reflected by high sperm DNA damage. This is the first report of increased in fructose concentration in seminal plasma from three azoospermic men's with Klinefelter's syndrome.

\section{Acknowledgements}

The authors would like to take this opportunity to extend my sincere thanks to Ministry of Health for providing financial support for the study. We also are grateful for the technical support of the Hanoi Medical University Hospital for the assay of the seminal fructose and zinc concentration.

\section{Conflict of interest}

Author declares that there is no conflict of interest.

\section{References}

1. WHO Laboratory manual for the Examination and processing of human semen. $5^{\text {th }}$ edn. Geneva: WHO Press; 2010.

2. Swerdloff RS, Wang C. The testis and male sexual function. $22^{\text {nd }}$ ed. In: Goldman L, Ausiello D, editors. Cecil Textbook of Medicine. Philadelphia (PA): Saunders Publisher; 2004:1472-1483.

3. Doshi H, Heana O, Hemali T. Zinc levels in seminal plasma and its relationship with seminal characteristics. Journal of Obstetrics and Gynecology of India. 2008;58:152-155.

4. Agarwal A, Bragais FM, Sabanegh E. Assessing sperm function. Urol Clin North Am. 2008;35(2):157-171.

5. Cooper TG. WHO laboratory manual for the Examination and processing of human semen. $5^{\text {th }}$ edn. Bern: WHO Press; 2010:1-157.

6. Lewis Jones DI, Aird IA, Biljan MM, et al. Effects of sperm activity on zinc and fructose concentrations in seminal plasma. Human Reproduction. 1996;11(11):2465-2467.

7. Videla E, Blanco AM, Galli ME, et al. Human seminal biochemistry: fructose, ascorbic acid, citric acid, acid phosphatase and their relationship with sperm count. Andrologia. 1981;13(3):212-214.

8. Schoenfeld C, Amelar RD, Dubin L, et al. Prolactin, fructose, and zinc levels found in human seminal plasma. Fertil Steril. 1979;32(2):206-208.

9. Biswas S, Ferguson KM, Stedronska J, et al. Fructose and hormone levels in semen: their correlations with sperm counts and motility. Fertil Steril. 1978;2(30):200-204

10. Carpino A, De Sanctis V, Siciliano L, et al. Epididymal and sex accessory gland secretions in transfusion-dependent beta-thalassemic patients: evidence of an impaired prostatic function. Exp Clin Endocrinol Diabetes. 1997;105(3):169-174.

11. Manivannan B, Bhande SS, Panneerdoss S, et al. Safety evaluation of longterm vas occlusion with styrene maleic anhydride and its non-invasive reversal on accessory reproductive organs in langurs. Asian J Androl. 2005;7(2):195-204.

12. Rajalakhshmi M, Sherma RS, David GF, et al. Seminal fructose in normal and infertile men. Contraception. 1989;39(3):299-306.

13. Gonzales GF. Function of seminal vesicles and their role on male fertility. Asian J Androl. 2001;3(4):251-258.

14. Sandstead HH, Prasad AS, Schulert AR, et al. Human zinc deficiency, endocrine manifestations and response to treatment. Am J Clin Nutr. $1967 ; 20(5): 422-442$

15. Omu AE, Dashti H, Othman S Al. Treatment of asthenozoospermic with zinc sulphate: andrological, immunological and obstetric outcome. Eur J Obstet Gynecol Reprod Biol.1998;79(2):179-184.

16. Saleh BOM, Hussain NK, Majid AY, et al. Status of Zinc and Copper Concentrations in Seminal Plasma of Male Infertility and Their Correlation with Various Sperm Parameters. The Iraqi postgraduate medical journal. 2008;7(1):76-80.

17. Male infertility Best Practice Policy Committee of the American Urological Association, Practice Committee of the American Society for Reproductive Medicine. Report on optimal evaluation of the infertile male. Fertil Steril. 2006;86(5 Suppl 1):S202-S209.

18. Kumar R. Thulkar S, Kumar V, et al. Contribution of investigations to the diagnosis of bilateral vas aplasia. ANZ J Surg. 2005;75(9)807-809.

19. Roe JH. A colorimetric method for the determination of fructose in blood and urine. J Biol Chem. 1975;107:5-22.

20. Johnsen O, Eliasson R. Evaluation of a commercially available kit for the colorimetric determination of zinc in human seminal plasma. Int $J$ Androl.1987;10(2):435-440.

21. Roe JH. A colorimetric method for the determination of fructose in blood and urine. J Biol Chem. 1934;107:15-22.

22. Franken DR, Oehninger S. Semen analysis and sperm function testing. Asian J Androl. 2012;14(1):6-13

23. Lu CJ, Chen F, Xu HR, et al. Standardization and quality control for determination of fructose in seminal plasma. J Androl. 2007;28(2):207-213.

24. Buckett WM, Lewis-Jones DI. Fructose concentrations in seminal plasma from men with nonobstructive azoospermia. Arch Androl. 2002;48(1):2327.

25. Orakwe JC, Chukwuezi FO, Ebu GU. True corrected seminal fructose in male infertility Nigerians a preliminary study. Nigerian Journal of Clinical Practice. 2010;13(1):84-86.

26. Mahmoud HH, Almashhedy LA, Abdul RSA. The key role of Zinc in enhancement of total antioxidant levels in spermatozoa of patients with Asthenozoospermia. Reproductive Biology and Endocrinology. $2014 ; 12: 3-8$.

27. Biswas S, Ferguson KM, Stedronska J, et al. Fructose and hormone levels in semen: their correlations with sperm counts and motility. Fertil Steril. 1978;30(2):200-204

28. Andrade Rocha FT. Sperm parameters in men with suspected infertility. Sperm characteristics, strict criteria sperm morphology analysis and hypoosmotic swelling test. J Reprod Med. 2001;46(6):577-582. 
29. Ndovi TT, Choi L, Caffo B, et al. Quantitative assessment of seminal vesicle and prostate drug concentrations by use of a noninvasive method. Clin Pharmacol Ther. 2006;80(2):146-158.

30. Raj V, Vijayan AN, Joseph K. Naked eye detection of infertility using fructose blue-a novel gold nanoparticle based fructose sensor. Biosens Bioelectron. 2014;54:171-174.

31. WHO Laboratory manual for the examination of human semen and semencervical mucus interaction. London: Cambridge University Press;1987.

32. Coppens L. Diagnosis and treatment of obstructive seminal vesicle pathology. Acta Urol Belg. 1997;65(2):11-19.

33. Buckett WM, Lewis-Jones DI. Fructose concentrations in seminal plasma from men with nonobstructive azoospermia. Arch Androl. 2002;48(1):2327.

34. Kise H, Nishioka J, Satoh K, et al. Measurement of protein C inhibitor in seminal plasma is useful for detecting agenesis of seminal vesicles or the vas deferens. J Androl. 2000;21(2):207-212.

35. Dohle GR. Inflammatory associated obstructions of the male reproductive tract. Andrologia. 2003;35(5):321-324

36. Yassa DA, Idriss WK, Atassi ME, et al. The diagnostic value of semina $\alpha$ - glucosidase enzyme index for sperm motility and fertilizing capacity. Saudi Medical Journal. 2001;22(11):987-991.

37. Björndahl L, Kvist U. Influence of seminal vesicular fluid on the zinc content of human sperm chromatin. Int J Androl. 1990;13(3):232-237.

38. Arver S, Eliasson R. Zinc and zinc ligands in human seminal plasma II. Contribution by ligands of different origin to the zinc binding properties of seminal plasma. Acta Physiol Scand. 1982;115(2):217-224.

39. Kvist U, Kjellberg S, Björndahl L, et al. Seminal fluid from men with agenesis of the wolffian ducts: zincbinding properties and effects on sperm chromatin stability. Int J Androl. 1990;13(4):245-252.

40. Saleh BOM, Hussain NK, Majid AY, et al. Status of Zinc and Copper Concentrations in Seminal Plasma of Male Infertility and Their Correlation with Various Sperm Parameters. The Iraqi postgraduate medical journal. 2008;7(1):76-80.

41. Fuse H, Kazama T, Ohta S, et al. Relationship between zinc concentrations in seminal plasma and various sperm parameters. Int Urol Nephrol. 1999;31(3):401-408.

42. Chia SE, Ong CN, Chua LH, et al. Comparison of zinc concentration in blood and seminal plasma and the various sperm parameters between fertile and infertile men. J Androl. 2000;21(1):53-57.

43. Eliasson R, Lindholme C. Zinc in human seminal plasma. Andrologia.1971;39(4):147-153.

44. Wong WY, Merkus HM, Thomas CM, et al. Effects of folic acid and zinc sulfate on male factor subfertility: a double-blind, randomized, placebocontrolled trial. Fertil Steril. 2002;77(3):491-498.

45. Caldamone AA, Freytag MK, Cockett AT. Seminal zinc and male infertility. Urology. 1979;13(3):280-281.
46. Antoniou LD, Shalhoub RJ, Sudhakar T, et al. Reversal of uraemic impotence by zinc. Lancet. 1977;2(8044):895-898.

47. Mankad M, Sathawara NG, Doshi H, et al. Seminal plasma zinc concentration and á-glucosidase activity with respect to semen quality. Biol Trace Elem Res. 2006;110(2):97-106.

48. Marmar JL, Katz S, Praiss DE, et al. Semen zinc levels in infertile and postvasectomy patients and patients with prostatitis. Fertil Steril. 1975;26(11):1057-1063.

49. Hartoma TR, Nahoul K, Netter A. Zinc, plasma androgens and male sterility. Lancet. 1977;2(8048):1125-1126.

50. Mahajan SK, Abbasi AA, Prasad AS, et al. Effect of oral zinc therapy on gonadal function in hemodialysis patients. A double-blind study. Ann Intern Med. 1982;97(3):357-361.

51. Wong WY, Merkus HM, Thomas CM, et al. Effects of folic acid and zinc sulfate on male factor subfertility: a double-blind, randomized, placebocontrolled trial. Fertil Steril. 2002;77(3):491-498.

52. Caldamone AA, Freytag MK, Cockett AT. Seminal zinc and male infertility. Urology. 1979;13(3):280-281.

53. Antoniou LD, Shalhoub RJ, Sudhakar T, et al. Reversal of uraemic impotence by zinc. Lancet. 1977;2(8044):895-898.

54. Abdul-Rasheed OF. The relationship between seminal plasma zinc levels and high molecular weight zinc binding protein and sperm motility in Iraqi infertile men. Saudi Med J. 2009;30(4):485-489.

55. Richthoff J, Spano M, Giwercman YL, et al. The impact of testicular and accessory sex gland function on sperm chromatin integrity as assessed by the sperm chromatin structure assay (SCSA). Hum Reprod. $2002 ; 17(12): 3162-3169$

56. Al-Daghistani HI, Hamad AW, Abdel-Dayem M, et al. Evaluation of Serum Testosterone, Progesterone, Seminal Antisperm Antibody, and Fructose Levels among Jordanian Males with a History of Infertility. Biochem Res Int. 2010;409-640.

57. Jayaraman V, Ghosh S, Sengupta A, et al. Identification of biochemica differences between different forms of male infertility by nuclear magnetic resonance (NMR) spectroscopy. $J$ Assist Reprod Genet. 2014;31(9):1195-1204

58. Ebisch IM, Thomas CM, Peters WH, et al. The importance of folate, zinc and antioxidants in the pathogenesis and prevention of subfertility. Hum Reprod Update. 2007;13(2):163-174

59. Ho E, Ames BN. Low intracellular Zinc induces oxidative DNA damage, disrupts P53, NFkappa B, and AP1 DNA binding, and affects DNA repair in a rat glioma cell line. Proc Natl Acad Sci USA. 2002;99(26):1677016775

60. Omu AE, Al-Azemi MK, Kehinde EO, et al. Indications of the Mechanisms Involved in Improved Sperm Parameters by Zinc Therapy. Med Princ Pract. 2008;17(2):108-116. 